Document downloaded from:

http://hdl.handle.net/10251/119993

This paper must be cited as:

Tobón, J.; Mendoza-Reales, O.; Restrepo, O.; Borrachero Rosado, MV.; Paya Bernabeu, JJ. (2018). Effect of Pyrogenic Silica and Nanosilica on Portland Cement Matrices. Journal of Materials in Civil Engineering. 30:1-10. https://doi.org/10.1061/(asce)mt.1943-5533.0002482

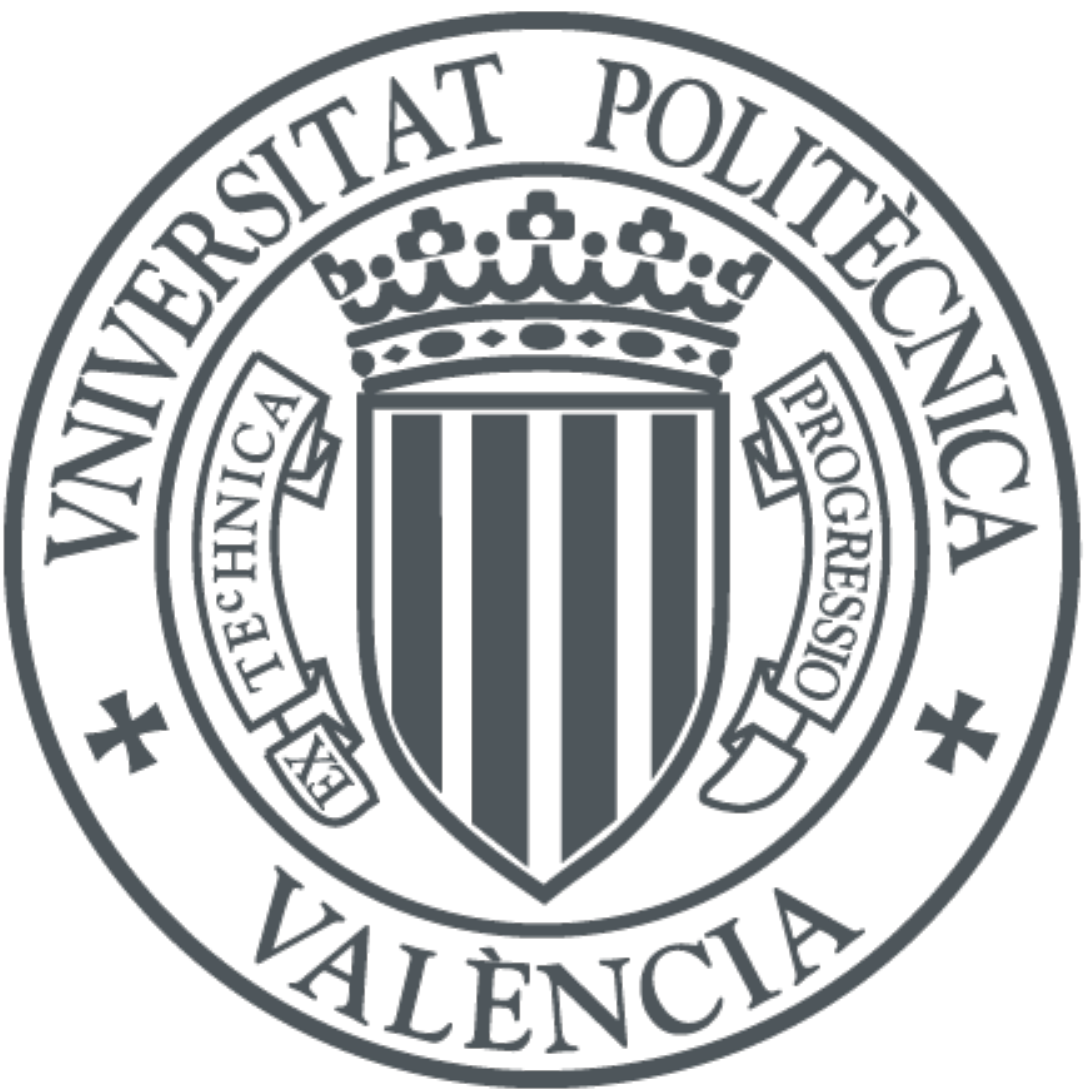

The final publication is available at

http://doi.org/10.1061/(asce)mt.1943-5533.0002482

Copyright American Society of Civil Engineers

Additional Information 


\title{
Effect of pyrogenic silica and nanosilica on Portland cement matrices
}

\author{
Jorge I. Tobón ${ }^{a^{*}}$, Oscar Mendoza Reales ${ }^{b}$, Oscar Jaime Restrepoc, María
} Victoria Borrachero ${ }^{d}$ and Jordi Payáe

\author{
a Professor, Ph. D., Grupo del Cemento y Materiales de Construcción CEMATCO - \\ Universidad Nacional de Colombia - Facultad de Minas - Medellín. Calle 75 \# 79ª - \\ 51 Bloque M17. jitobon@unal.edu.co. \\ b Posdoc researcher, D. Sc., Federal University of Rio de Janeiro. Ilha do Fundão, \\ Centro de Tecnologia, Bloco I Sala 110, Av. Horácio Macedo, 2030 - 101 - Cidade \\ Universitária. Rio de Janeiro, Brazil. ZIP: 21941-450. oscar@coc.ufrj.br. \\ ${ }^{c}$ Professor, Ph. D., Grupo del Cemento y Materiales de Construcción CEMATCO - \\ Universidad Nacional de Colombia - Facultad de Minas - Medellín. Calle 75 \# 79a - \\ 51 Bloque M17. ojrestre@unal.edu.co. \\ d Professor, Ph. D., Instituto de Ciencia y Tecnología del Hormigón, ICITECH, \\ Universitat Politècnica de València, Spain. Camino de Vera s/n 46071 VALENCIA \\ (Spain). vborrachero@cst.upv.es. \\ e Professor, Ph. D., Instituto de Ciencia y Tecnología del Hormigón, ICITECH, \\ Universitat Politècnica de València, Spain. Camino de Vera s/n 46071 VALENCIA \\ (Spain). jjpaya@cst.upv.es.
}

\section{ABSTRACT}

In this work the effect of pyrogenic silica and nanosilica on the properties of Portland cement matrices is compared. Two chemically and mineralogically similar mineral additions (amorphous silica), with different particle size and specific surface area, were used to prepare pastes and mortars with different solids substitutions of cement by silica. These samples were used to measure water and superplasticizer demand, setting time, hydration kinetics, water absorption by capillary suction and compressive strength. It was found that specific surface area, rather than particle size, played a crucial role in the amount of water and superplasticizer necessary to obtain a desired workability in pastes and mortars. Such water and superplasticizer demands had a delaying effect on the setting time and hydration kinetics of pastes. 
Nevertheless, compressive strength results at different curing ages of mortars were found to have a direct correlation with the porous structure of the matrix, rather than with the specific surface area of the silica particles. It was concluded that regardless of its higher specific surface area and greater effect on the fresh state properties of pastes, pyrogenic silica was less efficient than nanosilica to increase the compressive strength of mortars, being considered a less efficient pozzolanic material.

Keywords: Nanosilica, pyrogenic silica, hydration of cement, setting time, specific surface area of mineral addition

\section{INTRODUCTION}

Nanosilica (NS) is a very active mineral addition that reacts with $\mathrm{Ca}(\mathrm{OH})_{2}$ to form calcium silicate hydrate (C-S-H) during the hydration of Portland cement (Tobón et al. 2012) and improve the properties of the cement based matrix. NS is able to accelerate the hydration reaction of cement due to a seeding effect attributed to its high specific surface area (Björnström et al. 2004), causing a rapid formation of $\mathrm{Ca}(\mathrm{OH})_{2}$ at early ages. A direct consequence of this effect is the release of higher amount of hydration heat (Hou et al. 2013), shorter induction periods (Land and Stephan 2012) and higher compressive strength (Tobón et al. 2016). At early ages these effects from NS are associated with its nucleation effect, while at latter ages they are associated with its pozzolanic activity (Tobón 2011). The effectiveness of NS as a pozzolanic mineral addition depends on its average particle size and specific surface area (Singh et al. 2013).

Pyrogenic silica (PS) or fumed silica is a low density, micrometric particle size and high surface area agglomerate of amorphous silica produced by gas combustion (Gutsch et al. 2002). PS has been found to have a similar pozzolanic effect than NS on the performance of cement matrix, being surface area and particle size also important factors to determine its efficiency as mineral addition (Mobini et al. 2015). The main difference between NS and PS is that PS has a porous structure, which yields a higher specific surface area than NS. This arouses the question of which 
61 type of particle is more efficient as a pozzolanic mineral addition, NS with nanometric

62 particle size and lower specific surface area, or PS with micrometric particle size and

63 higher specific surface area. This research explores this question by comparing the

64 performance pastes and mortars blended with similar solid substitutions of NS and

65 PS by mass of cement, in both fresh and hardened states.

\section{EXPERIMENTAL}

\section{Materials}

The materials used in this work were Ordinary Portland cement produced by Cementos Argos S.A., powder of pyrogenic silica (PS) produced by Glassven, aqueous suspension of nanosilica (NS) produced by BASF Chemicals, a high range water reducing agent (SP) - G-type additive in accordance with ASTM C494-08a also produced by BASF Chemicals, and standardized silica sand complying with the ASTM C778. Raw materials were characterized through their chemical and mineralogical composition, specific surface area, and particle size distribution. Chemical composition was obtained by X-ray fluorescence (XRF) using B4Li2O7 pills following the ASTM C114-03 procedure. Mineralogical composition was obtained by X-ray diffraction (XRD) using a diffractometer with a copper radiation source in a $2 \theta$ interval from 2 to $70^{\circ}$, using $0.02^{\circ}$ steps with 30 seconds per step. Specific surface area was measured by N2 adsorption using BET theory. The density of PS and NS was measured following the ASTM C188 standard. Particle size distribution of microparticles and nanoparticles were measured by laser diffraction and dynamic light scattering respectively. NS was acquired as an aqueous suspension with a $40 \%$ solids concentration; the dispersing methodology was not disclosed by the manufacturer, but $\zeta$-potential experiments presented elsewhere (Tobón, Payá, and Restrepo, 2015) confirmed its stability at different pH values. The water contained in this suspension was removed by oven drying at $105^{\circ} \mathrm{C}$ to perform the mineralogical and particle size characterization of the nanoparticles.

\section{Tests on cement pastes}


A set of cement pastes blended with 1, 3, 5, and 10\% of NS, and 3, 5 and $10 \%$ of PS solid substitutions by mass of cement (bmoc) were prepared; water demand, SP demand, setting time and isothermal calorimetry measurements were carried out. All pastes were prepared in a planetary mixer, and their water demand was measured by finding the amount of water necessary to reach normal consistency following the ASTM C187 standard without using SP. The NS blended pastes were prepared by combining the NS suspension with the necessary amount of water to reach the desired water-to-cement ratio. This was mixed for 90 seconds, then cement was added and the paste was mixed following the ASTM C187 standard. The PS blended pastes were prepared by homogenizing cement and PS in a ball mill for 25 minutes per $\mathrm{kg}$ of mixture. Then the mixture was used to prepare the paste according to the ASTM C187 standard. For the pastes with SP, this additive was added in the mixing water at the beginning of the mixing procedure.

The SP demand was measured by finding the amount of SP necessary for a cement paste made with a fixed water-to-cementing material $(\mathrm{w} / \mathrm{cm})$ ratio of 0.32 to reach normal consistency. These two sets of pastes (one with variable w/cm and the other with variable SP for a given $w / \mathrm{cm}$ ) were used to measure their setting time following the ASTM C191 standard.

The effect of the two types of silica on the hydration kinetics of Portland cement was characterized by isothermal calorimetry at $25^{\circ} \mathrm{C}$ in a TAM Air Isothermal Calorimeter (TA Instruments, USA). Samples for this test were prepared using the different solid substitutions of PS and NS by mass of cement, a fixed w/cm of 0.50 , and no SP. Mixing was performed inside the calorimeter in glass ampoules using an admix device for 90 seconds without reference material.

\section{Tests on cement mortars}

Mortars were prepared using 1, 3, 5, and $10 \%$ of NS, and 3, 5 and $10 \%$ of PS solid substitutions by mass of cement and a cement-to-sand ratio of 2.75 following the ASTM C305 standard, and their flow were measured following the ASTM C1437 standard. A mortar without pozzolanic material was prepared as control mortar. The 
118

119

120

121

122

123

124

125

126

127

128

129

130

131

132

133

134

135

136

137

138

139

140

141

142

143

144

145

amount of water was fixed for all mortars at w/cm 0.55, and enough SP was added to reach a flow value between $105 \%$ and $115 \%$. The chosen w/cm for mortars was higher than that previously used for pastes to avoid using high amounts of superplasticizer that could mask the effects from NS and PS by reducing the mixing water and increasing the performance of the matrix (Shih et al. 2006). The NS blended mortars were prepared by combining the NS suspension with the necessary amount of water to reach the desired water-to-cement ratio. This was mixed for 90 seconds, and then the mortar was prepared following the ASTM C305 standard. The PS blended pastes were prepared by homogenizing cement and PS in a ball mill for 25 minutes per $\mathrm{kg}$ of mixture. For the mortars with SP, this additive was added in the mixing water at the beginning of the mixing procedure. Then the mixture was used to prepare the mortar according to the ASTM C305 standard. Mortars were poured in $4 \times 4 \times 16 \mathrm{~cm}$ prismatic molds, cured for 24 hours in a high humidity environment, then removed from the molds and cured in lime saturated water until reaching age of $3,7,28$, and 56 days. Compressive strengths of the mortars were measured following the ASTM C349 standards. Additionally, 7.6x15.2 cm cylinders were also cured in lime saturated water for 28 days and used to measure their water capillary suction following the procedure from the UNE 83982 standard.

A summary of the proportions used for all cement pastes and mortars studied in this work is presented in Table 1.

\section{RESULTS AND DISCUSSION}

\section{Materials characterization}

Chemical and mineralogical composition results for NS and PS, obtained by XRF and XRD, are presented in Table 2 and Figure 1 respectively. It was found that both NS and PS have high SiO2 contents; additionally, their diffraction patterns showed broad low intensity peaks aligned with that of cristobalite. This allows concluding that both materials are constituted mainly of amorphous silica and have high mineralogical purity. 
Particle size distribution and specific surface area results for NS, PS and cement are presented in Table 3. In Figure 2 are shown the particle size curves for NS and PS. It was found that both mineral additions presented a broad particle distribution within their size scale, being NS in the scale of nanometers and PS in the scale of micrometers. Regarding the specific surface area results it was found that PS presented almost three times more specific surface area than NS, which does not correspond with their particle size. PS presented a high specific surface area due to its pyrogenic origin, which generates very porous particles (Gutsch et al. 2002); this was supported by a measured density of $0.4 \mathrm{~g} / \mathrm{cm} 3$ for PS and $2.1 \mathrm{~g} / \mathrm{cm} 3$ for NS, showing that PS has very low density for a siliceous material, this value is proper of a porous material. NS presented a high specific surface area due to its small particle size (Ji 2005; Li et al. 2006; Qing et al. 2007).

\section{Water and SP demand}

One of the direct consequences of the usage of high specific surface area or very fine mineral additions is the increase in water and/or SP demand of the cement matrices (Björnström et al. 2004; Li 2004; Qing et al. 2007). This was studied in pastes and mortars through normal consistency and flow testing respectively. The water demand for each solid substitution was assessed by increasing the amount of water added to the paste until reaching normal consistency, while the SP demand was found by fixing w/cm in 0.32 and adding SP until reaching normal consistency. Water and SP demand results are presented in Figure 3. It can be seen that, as expected, both NS and PS increased the water and superplasticizer demand, being higher both demand values for PS in all cases. This can be related to the high porosity of PS predicted from its high surface area, which can not only adsorb water and SP on its surface, but it is also able to absorb them into its pores.

The specific surface area results presented in Table 3 were used to compute the total amount of solid surface area in $1000 \mathrm{~g}$ of each paste studied, i.e. the combined areas of cement and mineral addition taking into account the solid substitutions. Using the proportioning of each paste, the mass of each component was calculated to obtain $1000 \mathrm{~g}$ of paste, and then each mass was multiplied by its specific surface 
176

177

178

179

180

181

182

183

184

185

186

187

188

189

190

191

192

193

194

195

196

197

198

199

200

201

202

203

204

area and by added percentage to obtain the total surface area available in each paste. It was assumed that when in contact with water all particles maintained their dispersion state and its specific surface area was not modified. This is presented in Figure 4. It can be seen that when compared in terms of total surface area, the water and SP demand results of NS and PS follow a single general tendency, where the water demand increases linearly and the SP increases as a second degree polynomial, both with the total surface area available. This allows concluding that regardless of its particle size, the specific surface area describes the influence of the two silica materials studied better than their solid substitutions, which have similar chemical and mineralogical composition. This effect has already been reported in the literature for the rheological behavior of pastes blended with nano and micro silica (Mendoza Reales et al. 2017).

The water and SP demand of mortars were studied using a similar approach to that used with pastes, but using the flow of the mortar instead of the normal consistency of the paste as control parameter. The obtained results are presented in Figure 5. Similarly, to the results in paste, in mortars it was also found that both NS and PS increased the water and superplasticizer demand proportionally to the amount of them present in the mortars, being higher the demand values for PS in all cases.

The total surface area of cement and mineral addition available in $1000 \mathrm{~g}$ of mortar was also computed using the same method to obtain the total surface area of solids available in the pastes. The surface area contribution of sand was ignored because was considered very low and the same for all mortars. The water and SP demands were plotted versus the computed surface areas; the obtained results are presented in Figure 6. It was again found that NS and PS follow a single general tendency, where the water demand increases linearly and the SP increases as a second degree polynomial, both with the total surface area available.

\section{Time of setting}

The setting time of all the studied pastes, which is the difference between the final and initial setting times, is presented in Figure 7. For NS it was found that the setting 
205 time with and without SP remained approximately constant with respect to their 206 control paste, regardless of the amount of NS blended. For PS it was found that with

207 or without SP, the setting time increases proportional to the amount of PS blended, 208 which is also proportional to the amount of water or SP available in the paste. A 209 possible mechanism for this effect is that water at first becomes absorbed in the PS 210 (Burneau and Barres 1990) but is gradually released back into the paste during 211 mixing, which is one of the common uses of pyrogenic silica as a carrier agent. 212 Evidence of this phenomenon was identified during the mixing procedure as an 213 increase of the workability of the paste with the mixing time due to a modification of 214 its effective liquid-to-solid volumetric ratio. Additionally, high amounts of SP are able 215 to adsorb on the anhydrous cement grains and retard their hydration (Uchikawa et 216 al. 1997; Zhang and Somasundaran 2006; Zhang et al. 2001).

217 The time of setting results indicate that there is a competition between the retarding 218 action of SP and the acceleration from the nucleation and pozzolanic effects of the 219 mineral additions. It should be noticed that the referred retarding action of SP is 220 highly dependent on the type and amount of plasticizer used. In this research, a G221 type additive was used in accordance with ASTM C494-08a. Due to its lower water 222 and SP demand, NS is able to overcome the retarding action of SP and maintain the 223 setting time, while PS is not able to overcome such retardation effect due to its high 224 water and SP demand.

225 To better visualize how water and SP demand are related to the setting time results, 226 correlations plots between these variables are presented in Figure 8. The results 227 presented in this Figure, setting time vs water demand and setting time vs SP 228 demand, are a combination of the results presented in Figures 5 and 7, and 229 correspond to the same set of pastes, one without SP and variable $w / \mathrm{cm}$, and one 230 with variable SP and fixed $w / \mathrm{cm}$. It can be seen that there is a proportionality 231 between setting time and water demand, which was previously shown to be driven 232 by the amount of surface area in the paste: PS and NS presented two very distinct 233 behaviors. Both mineral additions increase the water demand, however, PS 234 increases the setting time while NS decreases it or remains the same. On the 
contrary, the SP demand, which was also shown to be driven by the surface area, presented a continuous trend in the form of a power law throughout all setting time results, regardless of the use of NS or PS. This indicates that amount of SP needed to obtained an adequate workability is the main variable controlling setting time, rather than the early pozzolanic effects of PS or NS.

\section{Calorimetry}

The obtained results for the NS blended pastes are presented in Figure 9. The first heat release peak corresponds to the amount of heat released during the dissolution of some of the anhydrous phases and formation of ettringite (AFt) from $\mathrm{C}_{3} \mathrm{~A}$ and sulfates (Scrivener et al. 2015). Its magnitude showed a typical value of cement with high $\mathrm{C}_{3} \mathrm{~A}$ content and small particle size. While the time at which the peak occurred for all NS blended samples was not modified, the total amount of energy released after 120 minutes showed a consistent increasing trend of energy up to $20.3 \%$ for $10 \%$ NS with respect to the control paste (Figure 9b). This shows that NS has an influence since the beginning of the hydration reaction.

The second heat release peak, which corresponds to the main calcium silicate hydrate $(\mathrm{C}-\mathrm{S}-\mathrm{H})$ and $\mathrm{Ca}(\mathrm{OH})_{2}$ formation, the second $\mathrm{AFt}$ formation and the $\mathrm{AFm}$ transformation (Scrivener et al. 2015), showed a slight acceleration when compared to the control paste in both height and location of the peak (Figure 9c). The heat release associated with this peak increased proportionally to the amount of NS blended in the paste up to $6.6 \%$. This suggests that NS is capable of accelerating the hydration reaction, and that this effect is proportional to the amount of NS present in the paste. This behavior has been attributed to the role of NS as nucleation seeds (Thomas et al. 2009)(Björnström et al. 2004), or to an early reaction between NS and $\mathrm{Ca}^{+2}$ ions in solution, which prevents the $\mathrm{Ca}^{+2}$ saturation and enhances the anhydrous phase dissolution (Gaitero et al. 2010). It is likely that the effects observed experimentally are a combination of both phenomena.

Regarding the total energy release (Figure 9d) it was found that the NS blended pastes released a higher amount of heat when compared to the control paste 
264 throughout all the testing time. Furthermore, it can be seen that there is an increase 265 of the total amount of energy with respect to the control sample, and this amount is 266 proportional to the amount of NS present in the paste. The highest increase was 267 found for the $10 \%$ NS paste, and was of $9.8 \%$ with respect to the control sample. 268 This confirms the positive effect of NS over the hydration kinetics of cement.

269 The same approach used for NS, was used to study the influence of PS over the 270 hydration kinetics of cement paste. Results are presented in Figure 10. It was found 271 that all samples blended with PS presented a lower amount of energy released in 272 the first heat release peak (Figure 10b). This can be associated with the high water 273 demand of the PS particles.

274 The second heat release peak (Figure 10c) was found to be decreased and 275 displaced to the right, i.e. retarded. This effect can be associated with water 276 absorbed in the PS porous structure and not being available to contribute to the 277 clinker dissolution and hydration. Additionally, it can be seen that despite an overall 278 retardation, there is a recovery of the time at which the second heat release peak 279 presented a maximum, and this recovery is proportional to the amount of PS in the 280 paste. This recovery can be associated with the filler effect of PS, which seems to 281 be competing with the adverse effect of the water demand of PS particles. The 282 energy release values for the same period showed a marginal increase of energy 283 released with respect to the control sample. This indicates that even though the heat 284 release peak becomes displaced to latter times, the presence of PS in the paste 285 does have some positive effect on the hydration of $\mathrm{C}_{3} \mathrm{~S}$.

286 In the total released energy results (Figure 10d) it can be seen that while the amount 287 of energy released by the PS blended samples was lower than the one from the 288 control samples during the first 1300 minutes of hydration, by the end of the testing 289 time the heat release rate of the PS blended samples becomes approximately equal 290 to that of the control sample. This indicates that the pozzolanic activity of NS appears 291 at the early stages of the hydration reaction of cement, while PS presents a slower 292 pozzolanic reaction or that occurs at longer times. 
The effects of NS and PS on the main heat release peak, i.e. the C-S-H and $\mathrm{Ca}(\mathrm{OH})_{2}$ formation, which was found to occur between 120 and 1480 minutes, are presented in Figure 11. This peak was chosen to compare the effects of NS and PS because both materials studied are pozzolans and their main effect is to enhance the C-S-H production. The total solids surface area available in $1000 \mathrm{~g}$ of paste was also used as comparison basis. It can be seen that even though PS has more surface area available, it has a lower effect on the amount of energy released. Nevertheless, PS enhances the amount of heat released probably due to physical effects rather than to pozzolanic activity.

\section{Capillary suction}

Mortars were prepared using a fixed $w / \mathrm{cm}$ of 0.55 and enough SP to obtain a flow value of $110 \pm 5 \%$, the amount of SP used for each mortar and its corresponding flow is presented in Table 4. The effect of NS and PS on the porosity of mortars was characterized by measuring their water absorption capacity by capillary suction after 28 days of curing. The obtained results are presented in Figure 12. Both the total amount of water absorbed and the rate of absorption over time can be used to understand the porous structure of the cement based matrix. When comparing with the control mortar, it can be seen that NS decreased both the total amount of water absorbed and the rate at which suction occurred, while PS maintained the same water suction rate, but increased the total amount of water absorbed by the matrix. This is a clear indication that NS is able to refine the porous structure of the matrix by increasing its tortuosity, which increases the difficulty of water to be absorbed, and decreases the total amount water absorbed which is associated with the pore volume, that is to say, NS diminishes the total volume of accessible pores. On the contrary, PS maintained the same water absorption rate and increased the total amount of water absorbed, this can be related to a lower pozzolanic activity and to the fact that PS itself is a highly porous material.

\section{Mechanical properties}


321 Compressive strength results for NS blended mortars are presented in Figure 13. It 322 can be seen that the 1 and 3\%NS mortars have compressive strength values similar 323 or lower to that of the control mortar, and only substitutions higher than $5 \%$ of NS 324 have significant effect over their compressive strength. The 10\% NS substitution 325 obtained the best result, reaching an average compressive strength after 28 days of curing of $73.7 \mathrm{MPa}$, which is a $70 \%$ increase when compared to the control mortar

327 at the same age. It should be also noticed even though the highest increase with 328 respect to the strength of the control mortar was obtained after 1 day of hydration 329 (116\% for the $10 \%$ NS mortar) over time an increase of average $80 \%$ was maintained 330 for all samples. This indicates that NS has a very strong early activity and is capable 331 of maintaining some of this activity over time.

332 Compressive strength results for the PS blended mortars are presented in Figure 333 14. It was found that from the third curing day ahead, the 5 and 10\% PS mortars 334 showed average compressive strength results higher than the control mortar. This 335 increase became greater up to the $28^{\text {th }}$ day of hydration for the $5 \%$ PS mortar, and 336 up to the $56^{\text {th }}$ day of hydration for the $10 \%$ PS mortar. From those ages ahead, the 337 compressive strength results become approximately stable. When comparing with 338 the compressive strength results obtained for NS, it can be seen that PS was less 339 efficient to increase the compressive strength of mortars, being the most notorious 340 difference between 10\% NS and 10\% PS at all ages. These differences in 341 compressive strength can be associated with the high SP content and less refined 342 porous structure of the PS blended mortars.

343 The 10\% NS reaches an average compressive strength after 28 days of curing 344 above of $73 \mathrm{MPa}$ (70\% improvement), while the mortar with 10\% PS was below 60 $\mathrm{MPa}$ for the same curing age (20\% improvement). This is a consequence of the 346 ability of mineral addition to modify the structure and volume of pores in the cement 347 matrix. This shows that a very high specific surface area is not enough if this is not 348 accompanied by a sufficiently small particle size. 
The role of the specific surface area of PS and NS was studied in cement pastes and mortars. It was found that while it has a great impact on the water and SP demand of the paste, the benefits of a higher surface area were not translated completely into the performance of pastes and mortars due to the need of high amounts of water necessary to obtain an adequate workability, which result in an increase in the volume of pores in them. Increased setting times of pastes with variable w/cm and no SP were identified for PS as consequence of the high amounts of water in the paste, while NS presented only a marginal effect. When fixing the w/cm and adding SP, it was found that the setting times of the PS blended pastes were also increased, this time due to the amount of SP present in the paste, while NS was able to compensate the retarding effect of SP and decrease the initial and final setting times. It should be noticed that this behavior is specific to the used SP, and is highly dependent on the amount used. This setting time results were found to be congruent with the amount of heat released in the main hydration peak, where it was found that regardless of having a higher specific surface area available, PS presented a lower amount of energy released during the $\mathrm{C}-\mathrm{S}-\mathrm{H}$ and $\mathrm{Ca}(\mathrm{OH})_{2}$ precipitation in comparison to NS.

An experimental observation was made for the PS blended mortars during mixing. A change in workability with the mixing time, from dry to fluid, was clearly identified for all the amounts of PS studied. This can be related to a release of the absorbed water in the PS particles due to the mechanical agitation. This delayed water release can also be associated with the increased setting times, decreased heat release, increased porosity and lower compressive strength increase. While NS was able to compensate for the dilution effect and further increase the compressive strength of mortars from the first day of hydration, the extent of the pozzolanic effect of PS was only of compensating the dilution effect to maintain the strength of mortars approximately equal to that of the control sample. The porous structure of the studied mortars was found to play an important role when explaining this effect. The capacity of a pozzolan to improve the mechanical properties of the cement matrix is not only governed by its potential to modify the kinetics of the hydration reaction, but also by its capacity to refine the porous structure. Despite its high SSA, PS was less efficient 
381 than NS to enhance the compressive strength of mortars due to the nature of its 382 pozzolanic reaction, which is expected to be slower, i.e. to occur at later ages and 383 its excessively high water demand.

\section{CONCLUSIONS}

385

- Specific surface area has a great impact on the water and SP demand in order to obtain an adequate workability, the benefits of a higher surface area were not translated completely into the performance of pastes and mortars.

- The demand water and SP, which are directly related to the specific surface area and to the porosity of the solids in the paste, drive the effect of the studied particles on the hydration kinetics and setting time.

397

- PS blended pastes have a delayed hydration kinetics and higher setting times when compared to the NS blended pastes due to their higher water and SP demand and to the nature of its pozzolanic activity which is expected to be slower.

402

- Despite its high SSA, PS was less efficient than NS to enhance the compressive strength of mortars due to an excess of water and SP in the mortars and to its delayed pozzolanic activity, which produced the lack of refinement of the porous structure.

- The capacity of a pozzolan to improve the mechanical properties of the

- The water absorption capacity of PS limited its pozzolanic activity by requiring the use of additional water and SP to achieve an adequate workability in pastes and mortars. cement matrix is not only governed by its potential to modify the kinetics of 
the hydration reaction, but also by its capacity to refine the porous structure. This shows that a very high specific surface area is not enough if this is not accompanied by a sufficiently small particle size.

\section{REFERENCES}

Björnström, J., Martinelli, A., Matic, A., Börjesson, L., and Panas, I. (2004).

"Accelerating effects of colloidal nano-silica for beneficial calcium-silicatehydrate formation in cement." Chemical Physics Letters, 392(1-3), 242-248.

Burneau, A., and Barres, O. (1990). "Comparative Study of the Surface Hydroxyl Groups of Fumed and Precipitated Silicas. 2. Chatracterization by infrared spectroscopy of the interacctions with water." Langmuir, 6(8), 1364-1372.

Gaitero, J. J., Campillo, I., Mondal, P., and Shah, S. P. (2010). "Small Changes Can Make a Great Difference." Transportation Research Record: Journal of the Transportation Research Board, 2141, 1-5.

Gutsch, A., Kramer, M., Michael, G., Muhlenweg, H., Pridohl, M., and Zimmerman, G. (2002). "Gas phase production of nanoparticles." KONA Powder and Particle Journal, 20pp(20), 24-37.

Hou, P., Kawashima, S., Kong, D., Corr, D. J., Qian, J., and Shah, S. P. (2013). "Modification effects of colloidal nanoSiO2 on cement hydration and its gel property." Composites Part B: Engineering, Elsevier Ltd, 45(1), 440-448.

Ji, T. (2005). "Preliminary study on the water permeability and microstructure of concrete incorporating nano-SiO2." Cement and Concrete Research, 35(10), 1943-1947.

Land, G., and Stephan, D. (2012). "The influence of nano-silica on the hydration of ordinary Portland cement." Journal of Materials Science, 47(2), 1011-1017.

Li, G. (2004). "Properties of high-volume fly ash concrete incorporating nanoSiO2." Cement and Concrete Research, 34(6), 1043-1049. 
Li, H., Zhang, M., and Ou, J. (2006). "Abrasion resistance of concrete containing nano-particles for pavement." Wear, 260(11-12), 1262-1266.

Mendoza Reales, O. A., Silva, E. C. C. M., Paiva, M. D. M., Duda, P., and Toledo, R. D. (2017). "The role of surface area and compacity of nanoparticles on the rheology of cement paste." Special Publication, 320, 25.1-25.13.

Mobini, M. H., Khaloo, A., Hosseini, P., and Esrafili, A. (2015). "Mechanical properties of fiber-reinforced high-performance concrete incorporating pyrogenic nanosilica with different surface areas." Construction and Building Materials, Elsevier Ltd, 101, 130-140.

Qing, Y., Zenan, Z., Deyu, K., and Rongshen, C. (2007). "Influence of nano-SiO2 addition on properties of hardened cement paste as compared with silica fume." Construction and Building Materials, 21(3), 539-545.

Scrivener, K. L., Juilland, P., and Monteiro, P. J. M. (2015). "Advances in understanding hydration of Portland cement." Cement and Concrete Research, Elsevier Ltd, 78, 38-56.

Shih, J., Chang, T., and Hsiao, T. (2006). "Effect of nanosilica on characterization of Portland cement composite." Materials Science and Engineering: A, 424(12), 266-274.

Singh, L. P., Karade, S. R., Bhattacharyya, S. K., Yousuf, M. M., and Ahalawat, S. (2013). "Beneficial role of nanosilica in cement based materials - A review." Construction and Building Materials, Elsevier Ltd, 47, 1069-1077.

Thomas, J. J., Jennings, H. M., and Chen, J. J. (2009). "Influence of Nucleation Seeding on the Hydration Mechanisms of Tricalcium Silicate and Cement." The Journal of Physical Chemistry C, 113(11), 4327-4334.

Tobón, J. I. (2011). "Evaluación del desempeño del cemento pórtland adicionado con nanopartículas de sílice." Hemisphere, Universidad Nacional de Colombia. 
463

464

465

466

467

468

469

470

471

472

473

474

475

476

477

478

479

480

481

482

483

484

Tobón, J. I., Payá, J. J., Borrachero, M. V., and Restrepo, O. J. (2012). "Mineralogical evolution of Portland cement blended with silica nanoparticles and its effect on mechanical strength." Construction and Building Materials, 36, 736-742.

Tobón, Jorge I., Jordi Payá, and Oscar J. Restrepo. 2015. "Study of Durability of Portland Cement Mortars Blended with Silica Nanoparticles." Construction and Building Materials 80: 92-97. doi:10.1016/j.conbuildmat.2014.12.074.

Tobón, J. I., Reales, O. a. M., and Payá, J. (2016). "Performance of white Portland cement matrixes blended with nanosilica and limestone for architectural applications." Advances in Cement Research, 1-10.

Uchikawa, H., Hanehara, S., and Sawaki, D. (1997). "The role of steric repulsive force in the dispersion of cement particles in fresh paste prepared with organic admixture." Cement and Concrete Research, 27(1), 37-50.

Zhang, R., and Somasundaran, P. (2006). "Advances in adsorption of surfactants and their mixtures at solid/solution interfaces." Advances in Colloid and Interface Science, 123-126(SPEC. ISS.), 213-229.

Zhang, T., Shang, S., Yin, F., Aishah, a., Salmiah, a., and Ooi, T. L. (2001). "Adsorptive behavior of surfactants on surface of Portland cement." Cement and Concrete Research, 31(7), 1009-1015. 


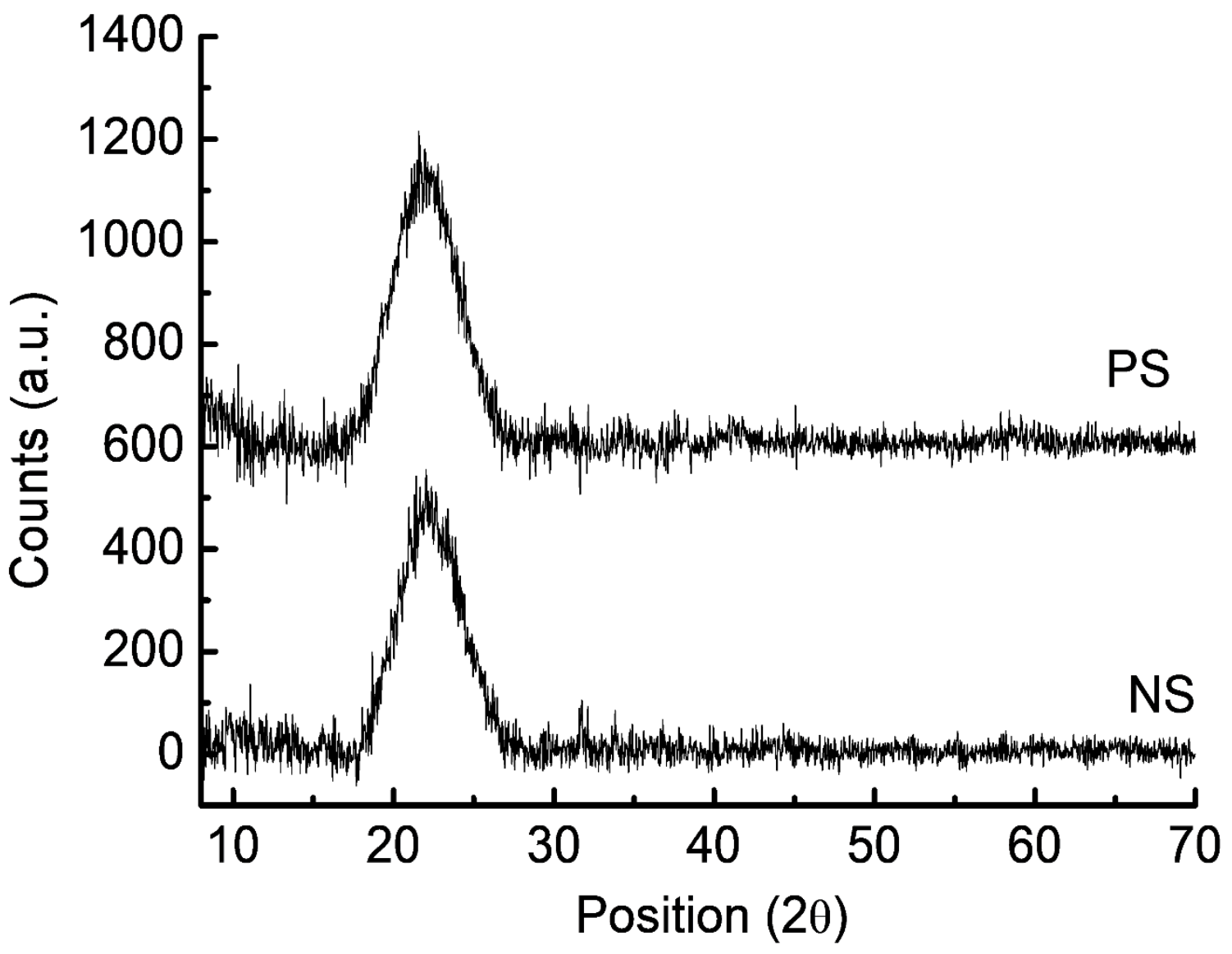

486 Figure $1-\mathrm{XRD}$ patterns of NS and PS 


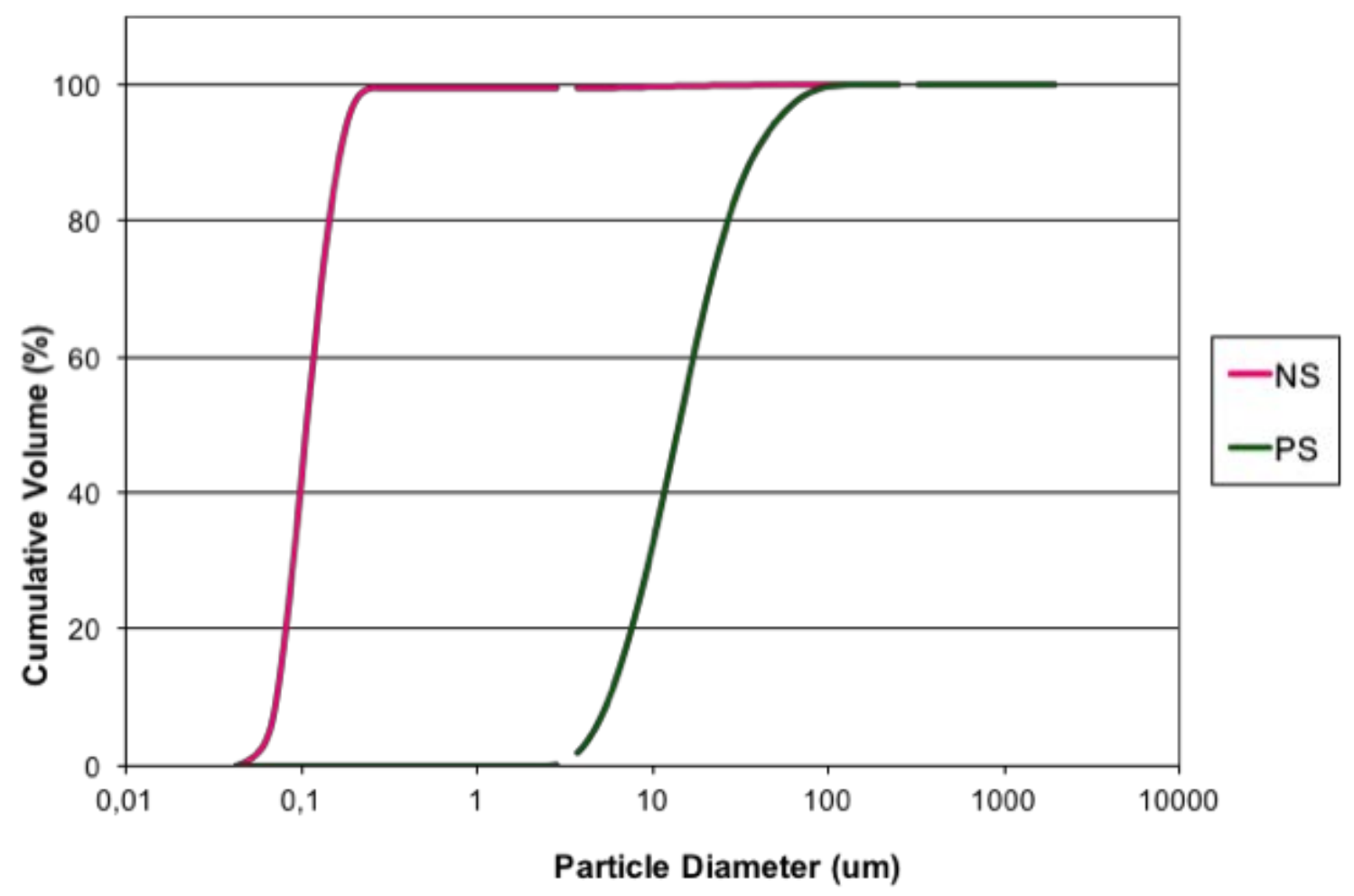

487

488 Figure 2 - Particle size curves for NS and PS
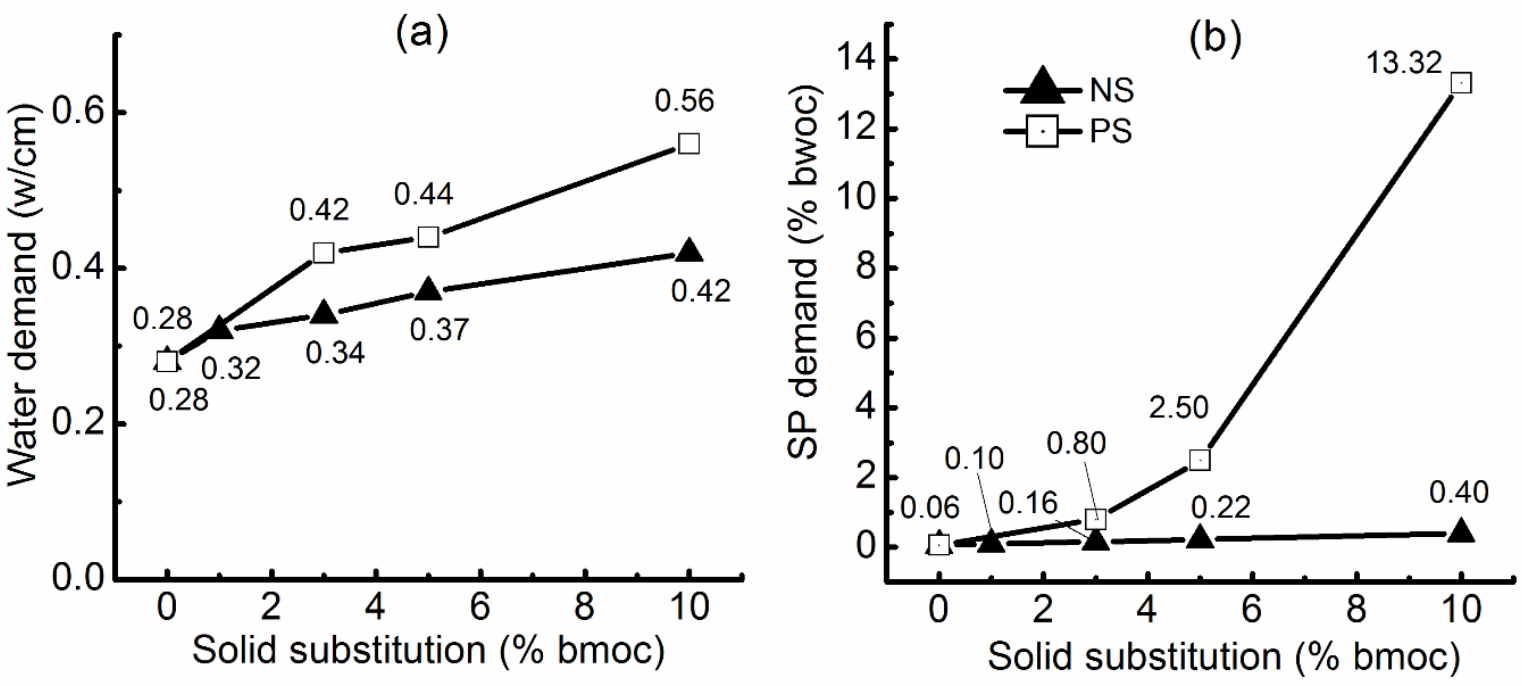

Figure 3 - (a) Water and (b) SP demand of cement pastes blended with NS and 491 PS (bmoc: by mass of cement) 

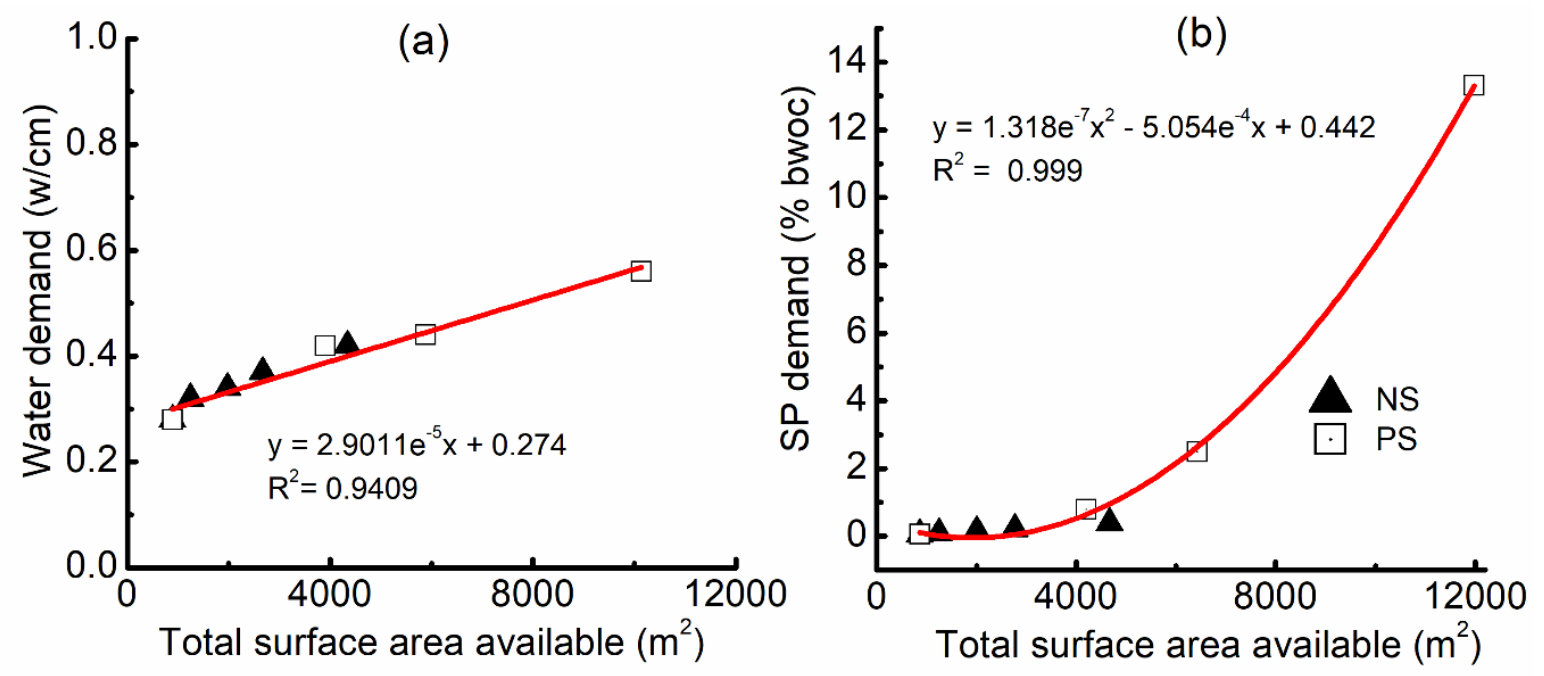

493 Figure 4 - (a) Water and (b) SP demand of cement pastes blended with NS and PS 494 versus total solids surface area available in $1000 \mathrm{~g}$ of paste
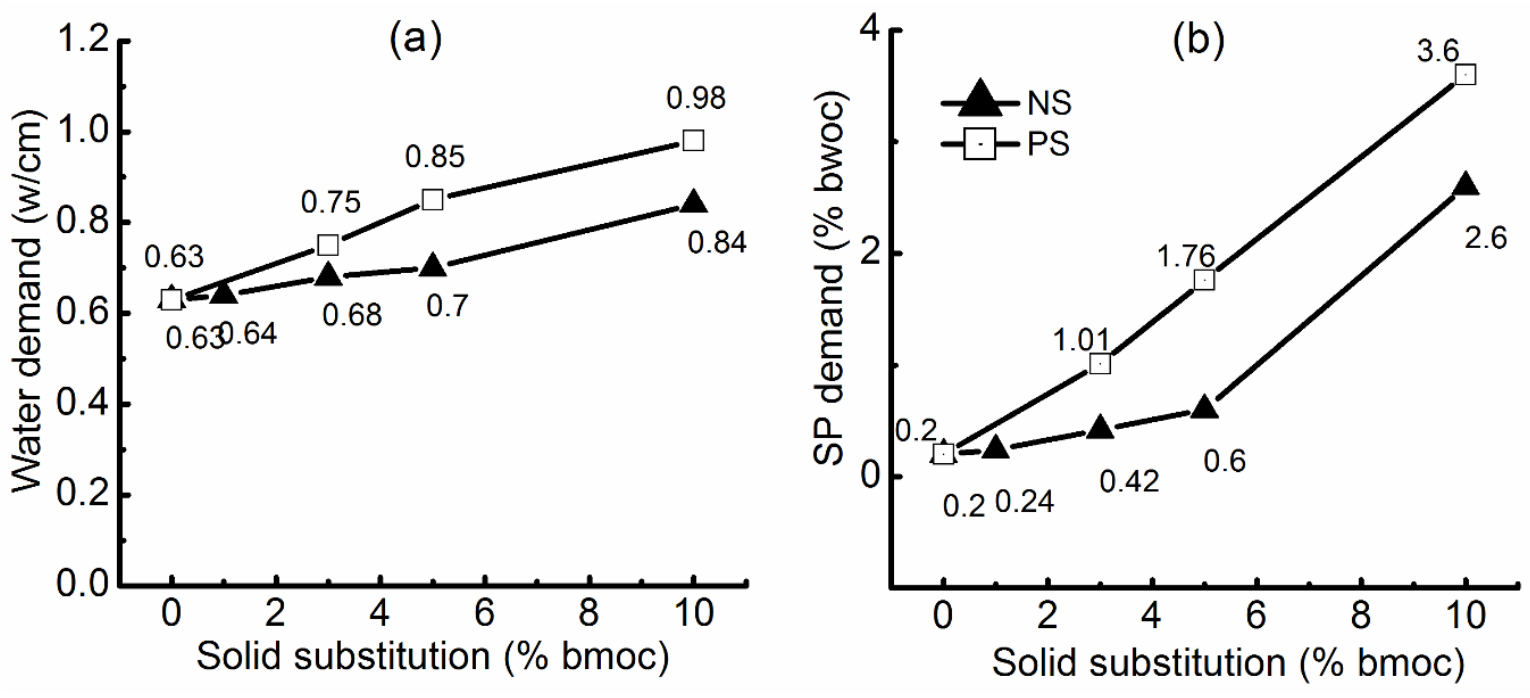

496 Figure 5 - (a) Water and (b) SP demand of cement mortars blended with NS and 497 PS (bmoc: by mass of cement) 

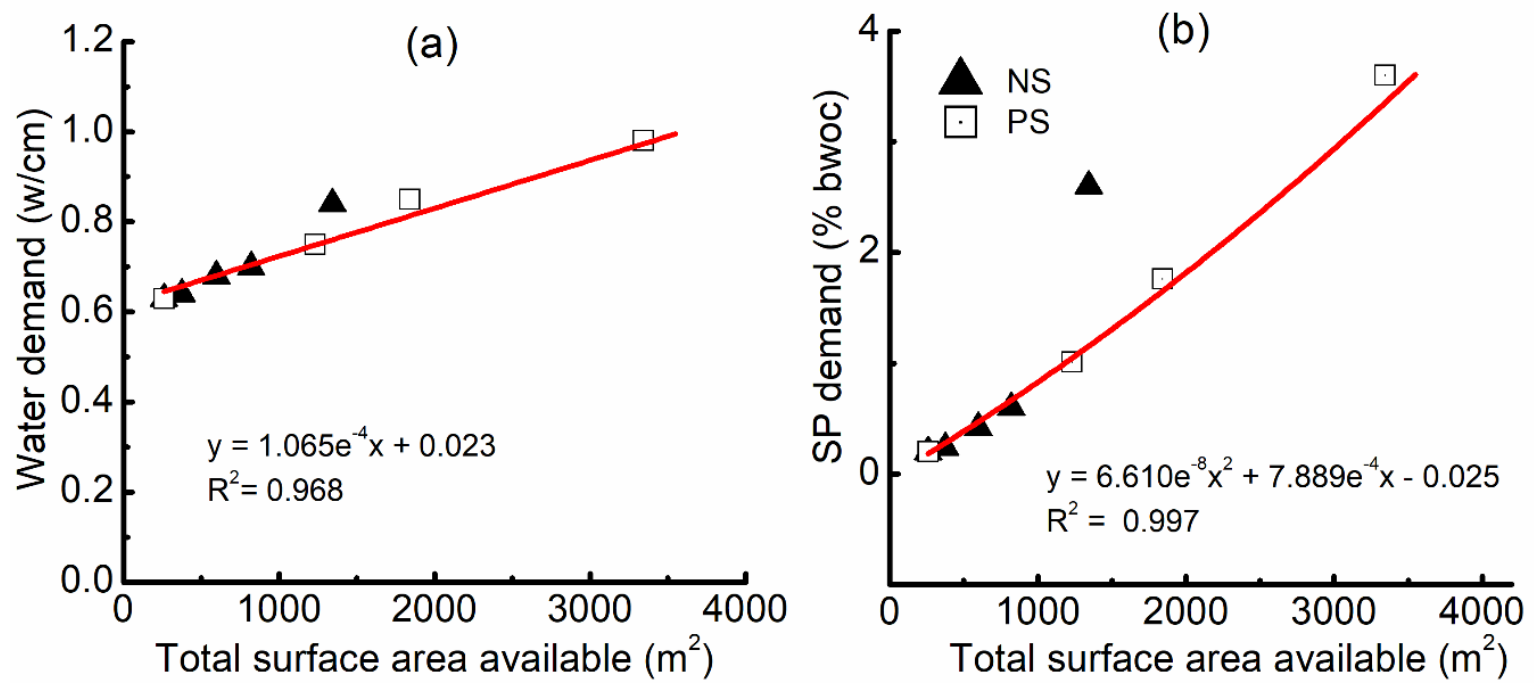

499 Figure 6 - (a) Water and (b) SP demand of cement mortars blended with NS and 500 PS versus total solids surface area available in $1000 \mathrm{~g}$ of mortar

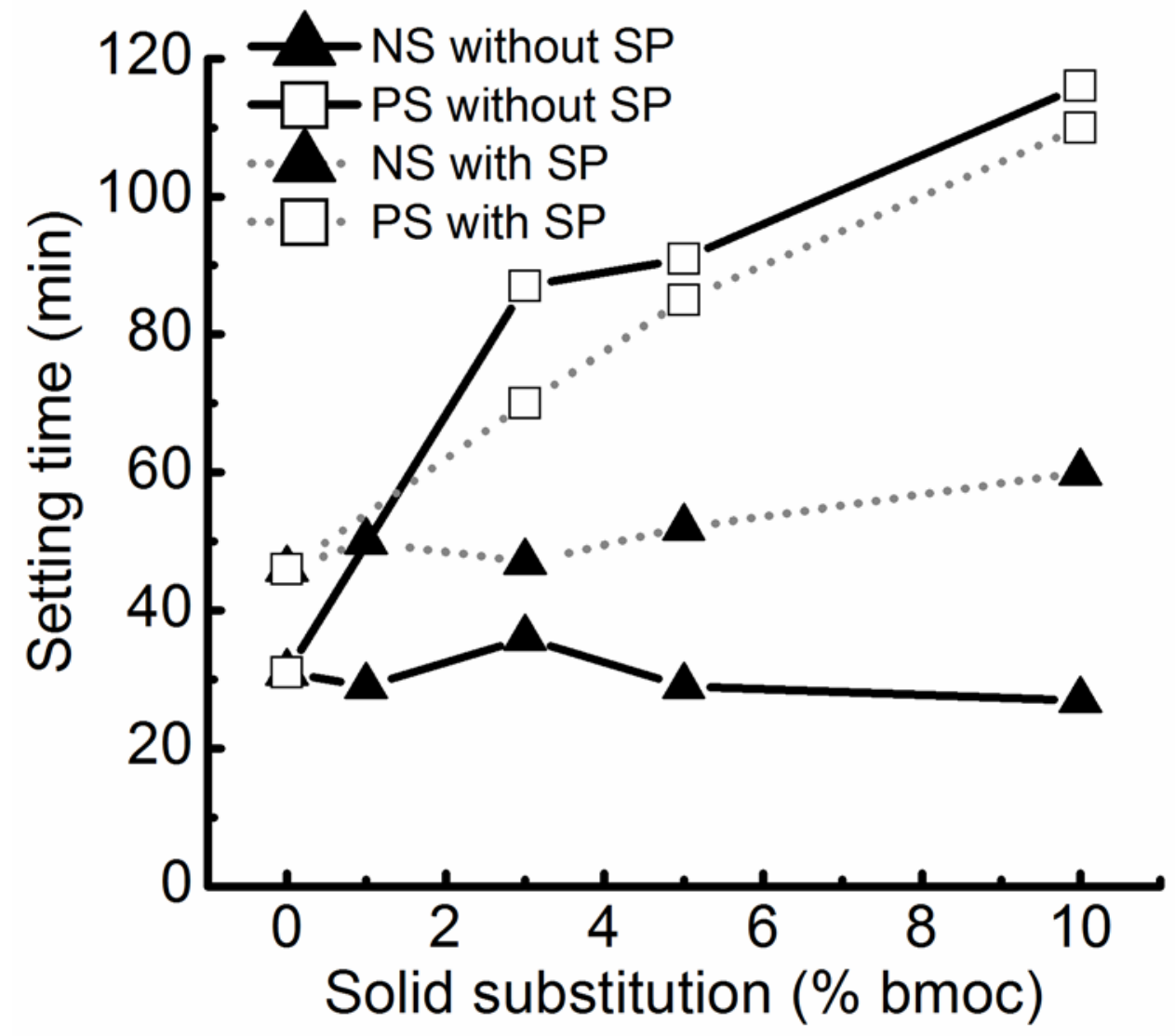

502 Figure 7 - Setting time for pastes blended with NS and PS with and without SP 503 (bmoc: by mass of cement) 
504

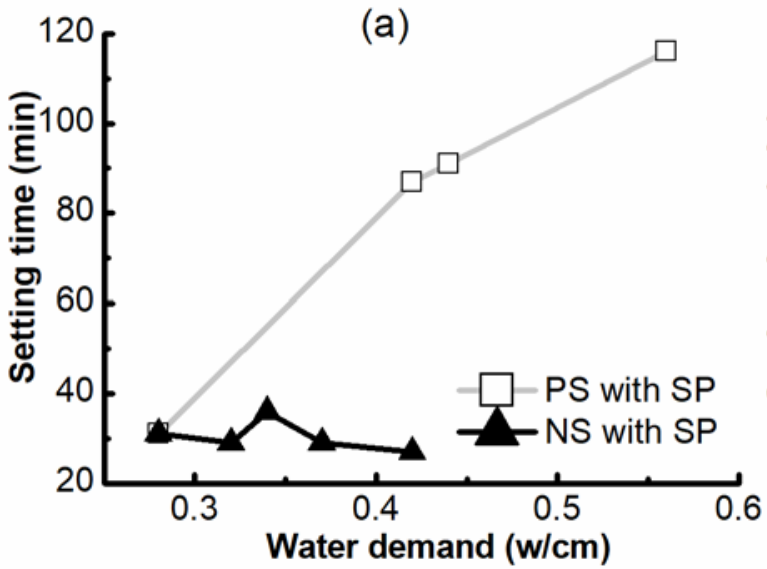

(b)

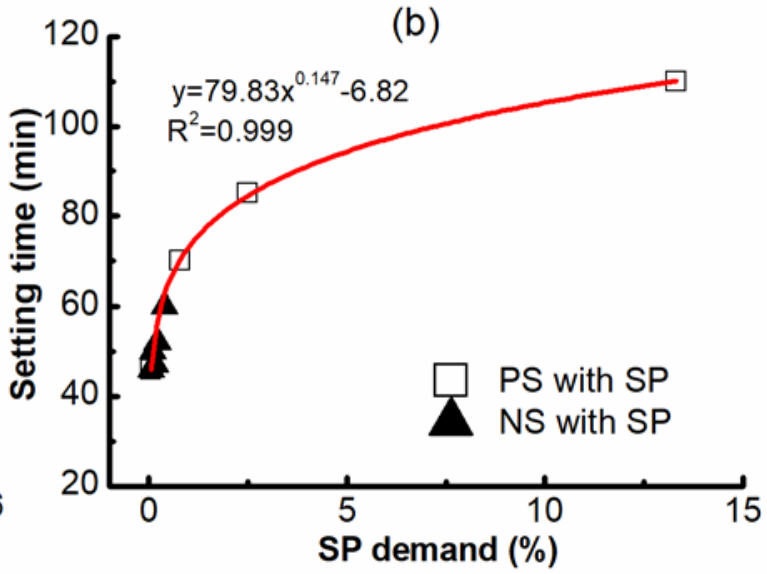

505 Figure 8 - Setting time of PS and NS blended pastes with and without SP versus 506 (a) water demand, (b) SP demand
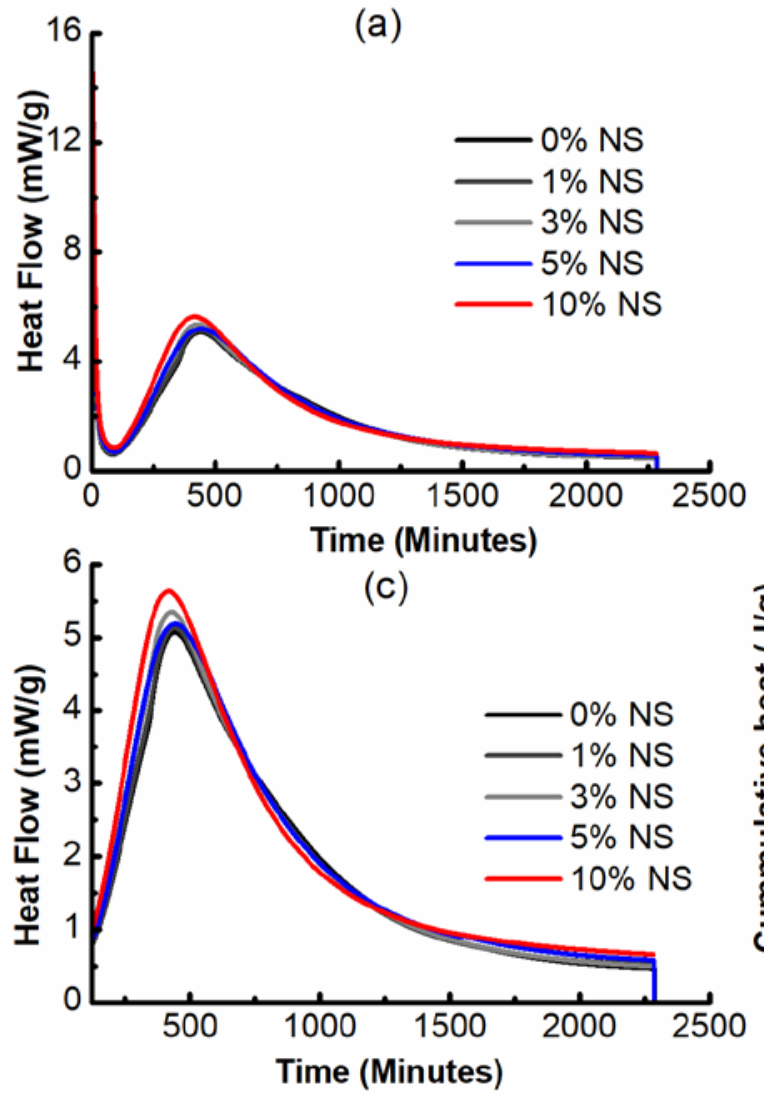

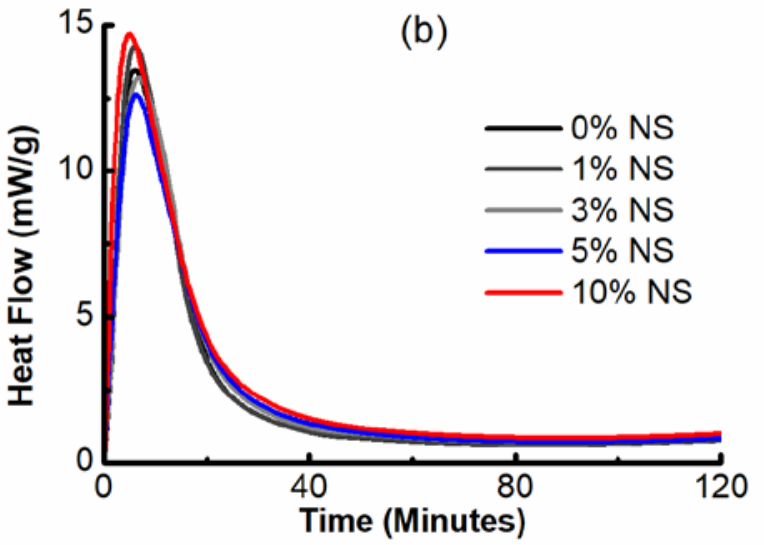

(d)

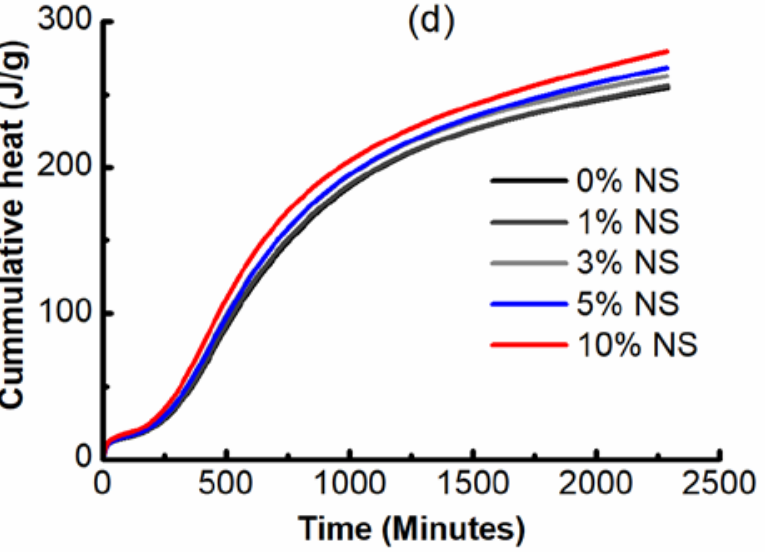

508 Figure 9 - Isothermal calorimetry for NS blended pastes with w/cm = 0.50: (a) heat 509 release curve, (b) dissolution heat release peak, (c) main hydration heat release 510 peak, (d) cumulative heat released 

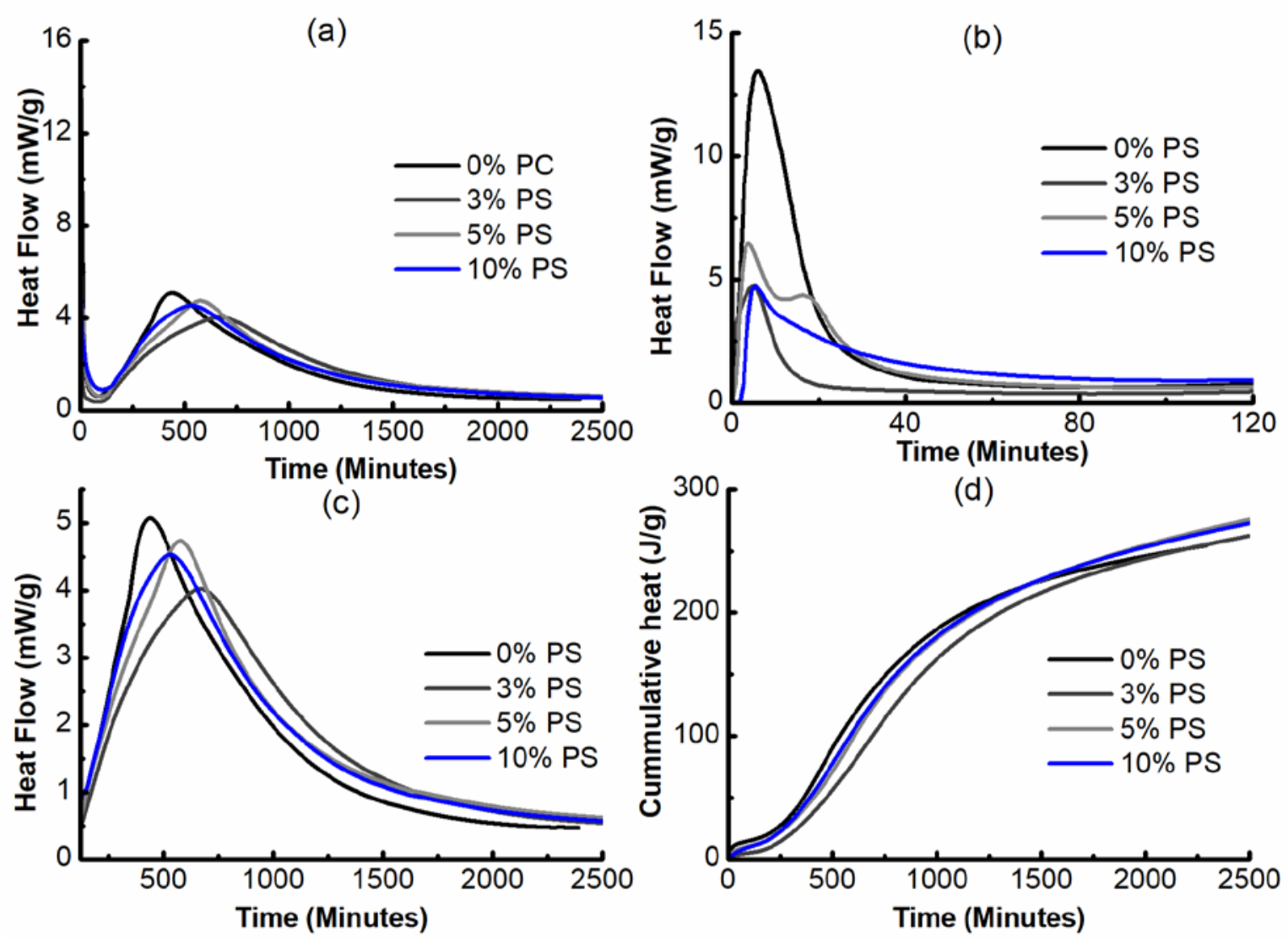

Figure 10 - Isothermal calorimetry results for PS blended pastes with $\mathrm{w} / \mathrm{cm}=0.50$ :

514 (a) heat release curve, (b) dissolution heat release peak, (c) main hydration heat 515 release peak, (d) cumulative heat released 


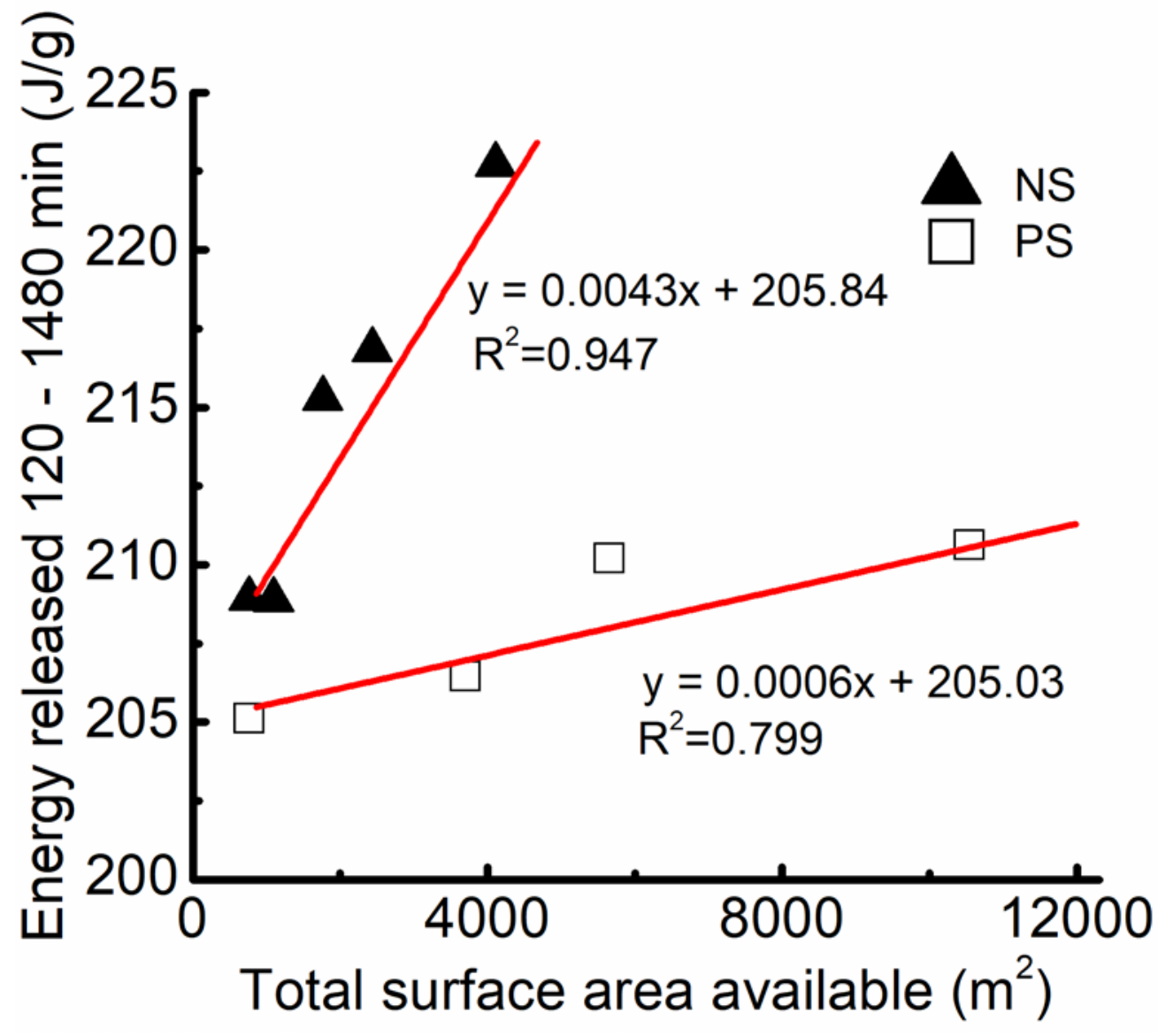

517 Figure 31 - Energy released between120 and 1480 minutes of hydration versus 518 total solids surface area available in $1000 \mathrm{~g}$ of paste 


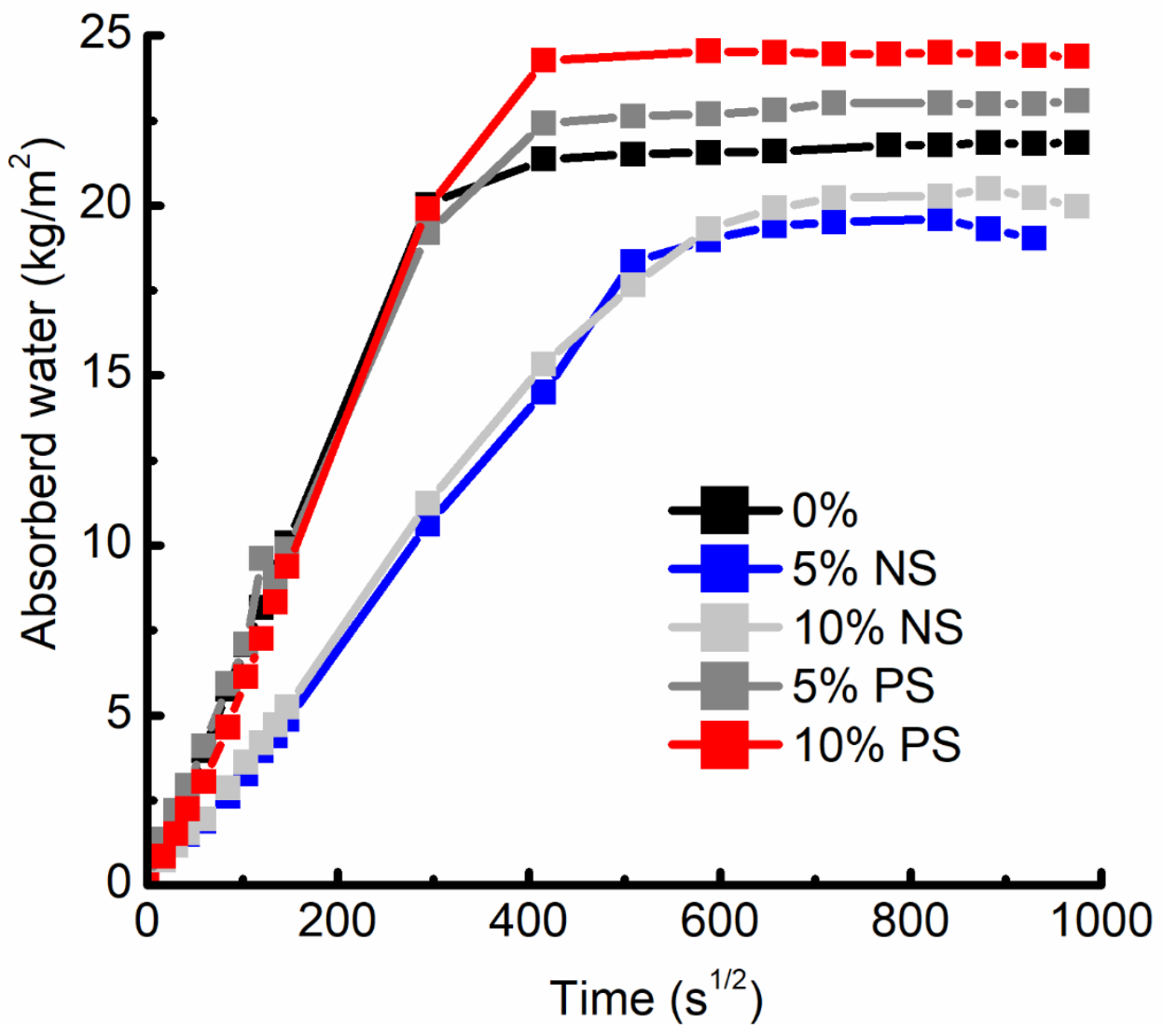

520 Figure 42 - Water absorption by capillary suction of mortars blended with NS and 521 PS 


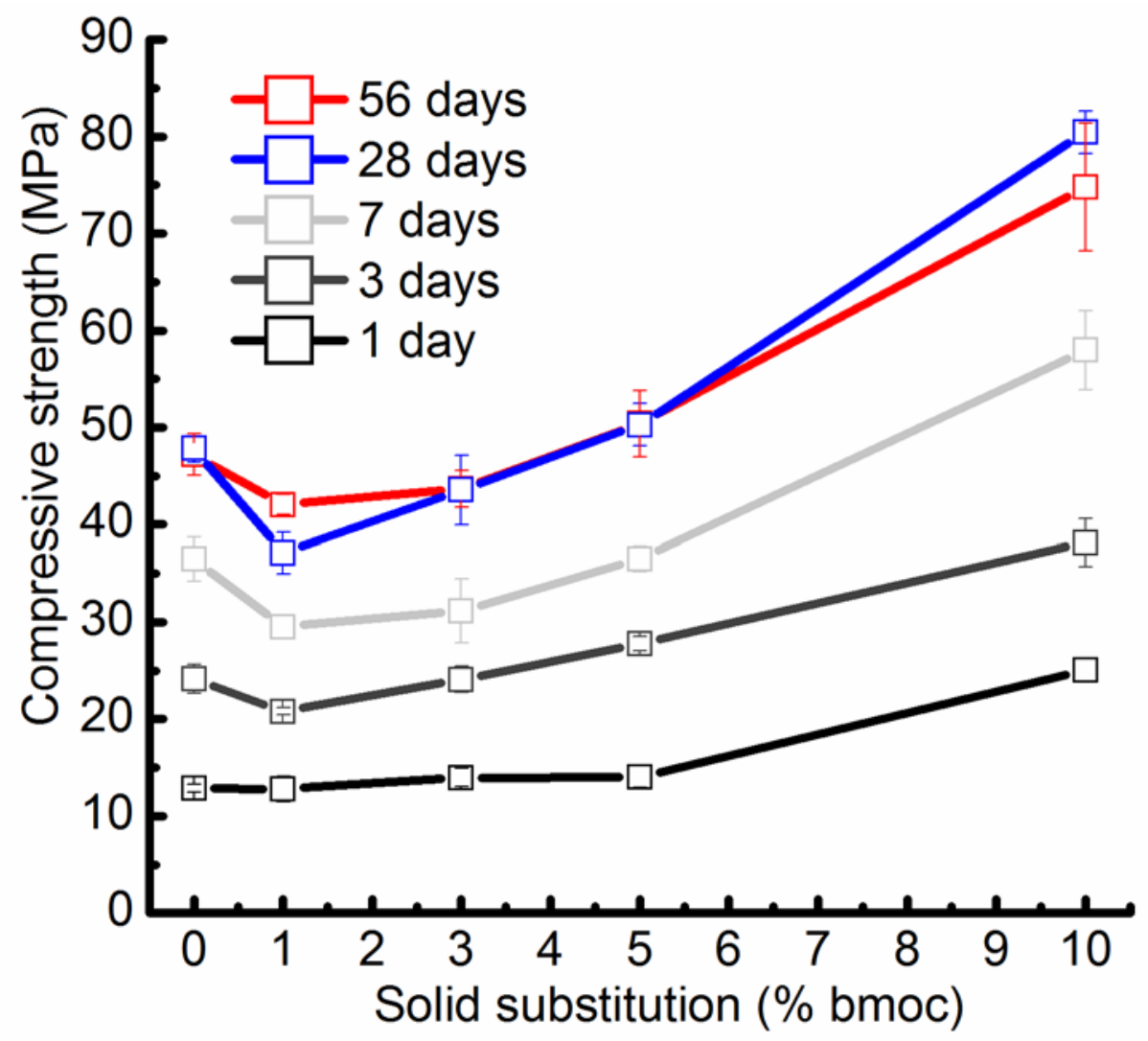

522

523 Figure 53 - Compressive strength development results of mortars blended with NS

524 (w/cm 0.55 and variable SP, (bmoc: by mass of cement) 


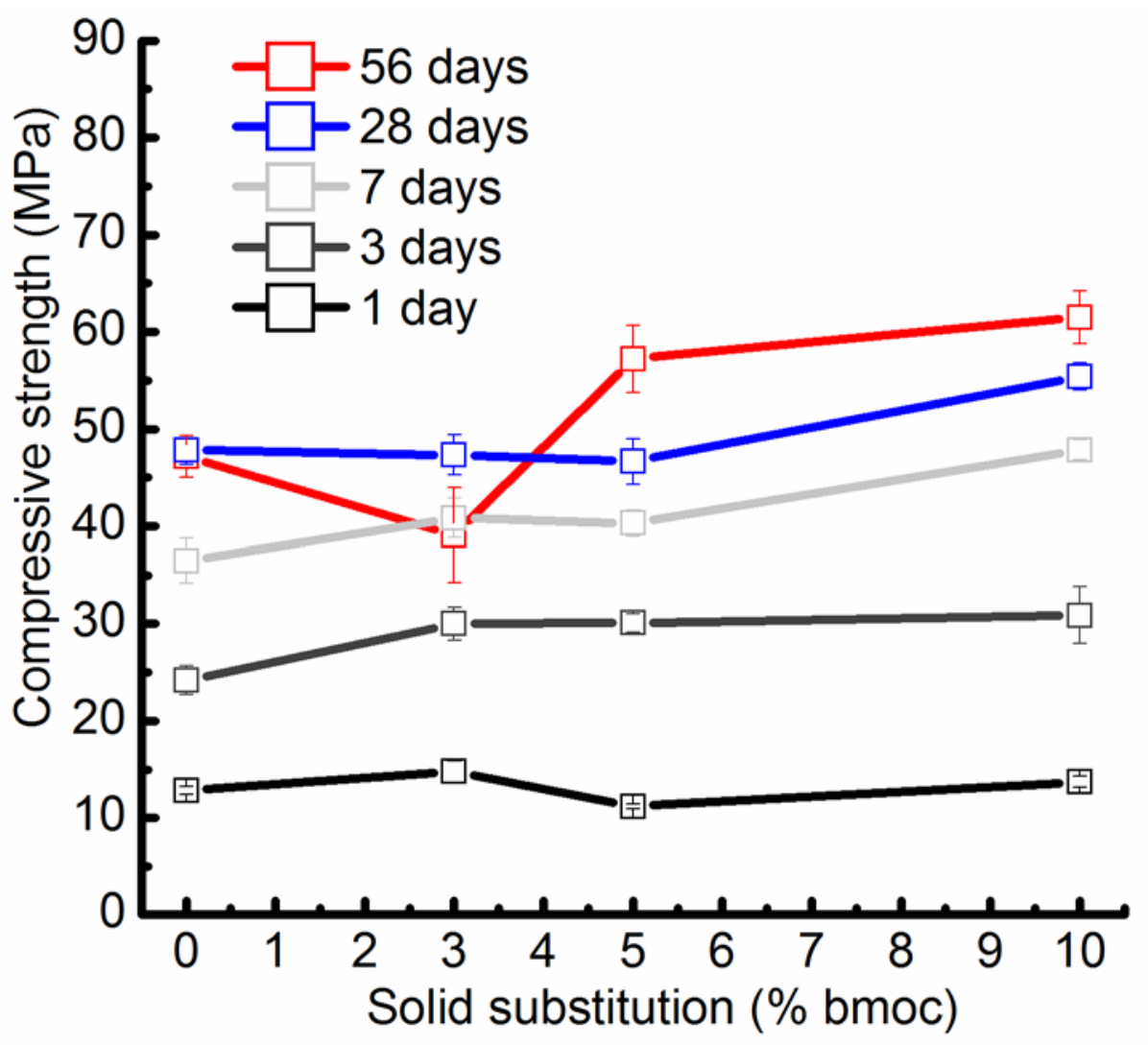

526 Figure 64 - Compressive strength results of mortars blended with PS (w/cm 0.55 527 and variable SP, (bmoc: by mass of cement) 
530 Table 1 - Summary of proportions used for pastes and mortars according to testing 531 method

\begin{tabular}{|c|c|c|c|c|}
\hline Test & $\mathrm{w} / \mathrm{cm}$ & SP (\%) & NS (\%) & PS (\%) \\
\hline \multicolumn{5}{|c|}{$\begin{array}{r}\text { Pastes } \\
\end{array}$} \\
\hline Water demand & $\begin{array}{c}\text { Variable (from } \\
0.28 \text { to } 0.56 \text { ) }\end{array}$ & Not used & \multirow{5}{*}{$1,3,5,10$} & \multirow{5}{*}{$3,5,10$} \\
\hline SP demand & 0.32 & $\begin{array}{l}\text { Variable (from } \\
0.06 \text { to } 13.32 \text { ) }\end{array}$ & & \\
\hline \multirow{2}{*}{ Setting time } & $\begin{array}{c}\text { Variable (from } \\
0.28 \text { to } 0.56 \text { ) }\end{array}$ & Not used & & \\
\hline & 0.32 & $\begin{array}{l}\text { Variable (from } \\
0.06 \text { to } 13.32 \text { ) }\end{array}$ & & \\
\hline Calorimetry & 0.50 & Not used & & \\
\hline \multicolumn{5}{|c|}{ Mortars } \\
\hline $\begin{array}{c}\text { Mechanical } \\
\text { properties } \\
\text { Capillary suction }\end{array}$ & 0.55 & $\begin{array}{l}\text { Variable (from } \\
0.2 \text { to } 3.6 \text { ) }\end{array}$ & $1,3,5,10$ & $3,5,10$ \\
\hline
\end{tabular}

533 Table 1 - Chemical composition of NS and PS by XRF (LOI: loss on ignition)

534

535

\begin{tabular}{ccc}
\hline $\begin{array}{c}\text { Component } \\
(\%)\end{array}$ & $\mathrm{NS}$ & $\mathrm{PS}$ \\
\hline $\mathrm{SiO}_{2}$ & 93.56 & 87.21 \\
$\mathrm{Al}_{2} \mathrm{O}_{3}$ & 0.00 & 0.00 \\
$\mathrm{FeO}_{2}$ & 0.39 & 0.13 \\
$\mathrm{CaO}$ & 0.22 & 0.13 \\
$\mathrm{MgO}$ & 0.13 & 0.13 \\
$\mathrm{Na} \mathrm{O}$ & 0.62 & 1.00 \\
$\mathrm{~K}_{2} \mathrm{O}$ & 0.02 & 0.01 \\
$\mathrm{SO}_{3}$ & 0.30 & 0.86 \\
$\mathrm{Cr}_{2} \mathrm{O}_{5}$ & 0.04 & 0.00 \\
$\mathrm{MnO}$ & 0.01 & 0.01 \\
$\mathrm{P}_{2} \mathrm{O}_{5}$ & 0.13 & 0.12 \\
$\mathrm{TiO}_{2}$ & 0.02 & 0.04 \\
$\mathrm{LOI}$ & 4.46 & 10.01 \\
\hline
\end{tabular}

536 
538 Table 3 - Particle size distribution and specific surface area results for NS and PS 539

\begin{tabular}{lcccc}
\hline Particle & $\begin{array}{c}\text { Particle size }- \\
\mathrm{d}_{10}(\mu \mathrm{m})\end{array}$ & $\begin{array}{c}\text { Particle size }- \\
\mathrm{d}_{50}(\mu \mathrm{m})\end{array}$ & $\begin{array}{c}\text { Particle size }- \\
\mathrm{d}_{90}(\mu \mathrm{m})\end{array}$ & $\begin{array}{c}\text { Specific } \\
\text { surface area } \\
\left(\mathrm{m}^{2} / \mathrm{g}\right)\end{array}$ \\
\hline NS & 0.066 & 0.098 & 0.164 & 51.40 \\
PS & 4.7 & 11.8 & 33.4 & 147.85 \\
\hline
\end{tabular}

540

541

542

543 Table $4-$ SP demand of mortars with a fixed w/cm of 0.55 to obtain normal flow

\begin{tabular}{cccc}
\hline Sample & w/cm & SP (wt \%) & Flow (\%) \\
\hline $0 \%$ & & 0.20 & 114.8 \\
$1 \%$ NS & & 0.24 & 112.6 \\
$3 \%$ NS & & 0.42 & 105.2 \\
$5 \%$ NS & 0.55 & 0.60 & 106.0 \\
$10 \%$ NS & & 2.60 & 108.9 \\
$3 \%$ PS & & 1.00 & 111.1 \\
$5 \%$ PS & & 1.76 & 111.4 \\
$10 \%$ PS & & 3.60 & 111.6 \\
\hline
\end{tabular}

544

545

546 